\title{
THE POTENTIAL GEOGRAPHICAL DISTRIBUTION OF BACTROCERA DORSALIS (DIPTERA: TEPHRIDIDAE) IN CHINA BASED ON EMERGENCE RATE MODEL AND ARCGIS
}

\author{
Ningbo Wang ${ }^{1}$, Zhihong $\mathrm{Li}^{1{ }^{1, *}}$, Jiajiao $\mathrm{Wu}^{2}$, Edwin G. Rajotte ${ }^{3}$, Fanghao \\ $\mathrm{Wan}^{4}$, Zhiling Wang ${ }^{5}$ \\ ${ }^{1}$ Department of Plant Protection and Quarantine, China Agricultural University, Beijing, \\ 100193, China \\ 2 Plant Quarantine Lab, Guangdong Inspection and Quarantine Technology Center, \\ Guangzhou, 510623, China \\ 3 Department of Entomology, Penn State University, 501 ASI Building, University Park, PA \\ 16802, USA \\ 4 Institue of Plant Protection, Chinese Academy Agricultural Sciences, Beijing, 100081, \\ China \\ ${ }^{5}$ Beijing Academy of Agriculture and Forestry Sciences, Beijing, 100089, China \\ * Corresponding author, Address: Department of Plant Protection and Quarantine, College \\ of Agronomy and Biotechnology, China Agricultural University, Beijing 100193, China, \\ Tel: 010-62731299, Fax:+86-10-62733404, Email: lizh@cau.edu.cn
}

Abstract: The oriental fruit fly, Bactrocera dorsalis (Handel) (Dipteral: Tephrididae), is the important insect pest of fruits and vegetables in tropical and subtropical areas. It is necessary to know the potential geographical distribution of this pest in order to monitor and control it effectively. Pupal development takes place in the soil and is regulated by two key factors; soil temperature and moisture. These factors are primary determinants of fruit fly distribution. In this study, the potential geographical distribution of B. dorsalis from Jan. to Dec. in China was predicted based on the soil temperature and moisture data of Chinese meteorologic stations, the ER (Emergence rate) model constructed from empirical biological data, and analysis with ArcGIS. The ER data were obtained by observing the emergence of 7560 cultured pupae using a crossover design of 7 soil temperature grades and 6 soil moisture grades. The ER model $(\mathrm{Z}=-0.0036 \mathrm{X} 2-0.0001 \mathrm{Y} 2+0.1681 \mathrm{X}+0.0123 \mathrm{Y}-1.5170)$ was established with stepwise regression method where emergence rate $(\mathrm{Z})$ is a function of soil temperature $(\mathrm{X})$ and soil moisture $(\mathrm{Y})$. According to reported geographical

Please use the following format when citing this chapter:

Wang, N., Li, Z., Wu, J., Rajotte, E.G., Wan, F. and Wang, Z., 2009, in IFIP International Federation for Information Processing, Volume 293, Computer and Computing Technologies in Agriculture II, Volume 1, eds. D. Li, Z. Chunjiang, (Boston: Springer), pp. 399-411. 
distributions in the world, four categories were used to describe different levels of suitability for B. dorsalis in China, including negligible $(0 \leq \mathrm{ER} \leq 0.01)$, low $(0.01<\mathrm{ER} \leq 0.2)$, moderate $(0.2<\mathrm{ER} \leq 0.45)$ and high $(0.45<\mathrm{ER} \leq 1)$. The potential geographical distribution and suitable levels for every month in China were obtained and showed that main parts of the distribution were south of $\pm 35^{\circ} \mathrm{N}$, and most regions in China had high suitability levels from May to September. Further analysis showed the desireability of strengthening monitoring in the north parts of China from Apr. to Oct. and to institute whole year monitoring in Guangdong, Guangxi, Yunnan, and Hainan provinces.

Keywords: Bactrocera dorsalis, potential geographical distribution, emergence rate, plant quarantine, ArcGIS

\section{INTRODUCTION}

The oriental fruit fly, Bactrocera dorsalis (Hendel) (Diptera: Tephrididae), originates from Taiwan and Ryukyu Islands and is a serious quarantine pest of fruits with a wide host area in tropical and subtropical countries (Huang Suqing et al., 2005). Bactrocera dorsalis has reportedly spread abroad to about 20 countries in North America, Oceania and Asia by IIE (International Institute of Entomology) as well as Europe and the Mediterranean Plant Protection Organization (IIE, 1994). In addition, B.dorsalis' host is continually expanding; 150 host species in 1960 (Christenson et al., 1960), 250 species in 2003 (Liang Guanghong et al., 2003) and in 2005. Presently, this fruit fly infects more than 300 species of fruits and vegetables from 46 families in southern provinces of China like Fujian, Hainan, Guangdong, Guangxi, Hunan, Guizhou, Yunnan, and Sichuan (Huang Suqing et al., 2005; Huang Kehui et al., 2005).

The oriental fruit fly can have three to eleven generations yearly in China, but mainly has four to eight generations, and its growth periods were 19d under $24^{\circ} \mathrm{C}$, and $32.5 \mathrm{~d}-35 \mathrm{~d}$ under $33^{\circ} \mathrm{C}$ in Yunnan province. The emergence rate of oriental fruit fly was between $80 \%$ and $90 \%$ in these areas. However, overwintering is variable and many generations are staggered resulting in different insect states occurring at the same time and place (Liang Guanghong et al., 2003; Liang Guangqin et al., 1993; Zhang Qingyuan et al., 1998; Zhou Yousheng et al., 1996; Jiang Xiaolong et al., 2001).

Knowledge of the geographical distribution of insect pests is necessary to properly monitor and manage them. Consequently, suitability analysis methods have gained attention in recent years. Suitability analyses are estimated from simple ecological estimates, climographic analysis (Cook et al., 1921, 1931), similarity distance of agricultural climate (Wei Shuqiu, 

ArcGIS

1984), Geographical Information System (Wu Yufen, 2005), Ecological Niche Models (Wang Yunsheng et al., 2007), CLIMEX (Sutherst et al., 1991, 2005; Song Hongmin et al., 2004; Stephens et al., 2007 ; Hou Bohua et al., 2005; Chen Lin et al., 2006), GARP (Zhou Guoliang et al., 2007), DIVAGIS (Ge Quanqing et al., 2006 ; Hernandez, 2006), MAXENT (Elith et al., 2006; Wang Yunsheng et al., 2007) and so on. Moreover, software based on ecological niches including BIOMAPPER, BRT, GAM, GLM. The characteristic of these methods was more accurate and more simply than ever because many suitability analysis methods are based on exact software and comprehensive influence factors of corresponding pest.

Several methods have been used to predict the potential geographical distribution of oriental fruit fly. The first used fuzzy mathematics (Zhang Runjie et al., 2005) and showed that the potential geographical distribution of $B$. dorsalis in China occurred in regions south of $25^{\circ} \mathrm{N}$ including the Sichuan basin and part of Guizhou province The region between $25^{\circ} \mathrm{N}$ and the Changjiang River was less suitable, and other regions of China were unsuitable (Fan Jinan et al., 1998). The second method used CLIMEX and showed that the most suitable areas are in South China including Guangdong, Hong Kong, Hainan and Guangxi Zhuang Automomous Region, moderately suitable areas includes Yunnan, Sichuan, Southwest China and some parts of Fujian province, the suitability drops in some parts of Hunan, Hubei, Jiangxi and Zhejiang provinces. Unsuitable areas included the northern part of the Yangzi River (Hou Bohua et al., 2005). Stephens et al (2007) reported the current and future potential geographical distribution using CLIMEX, but the prediction did not align well with real distribution, especially in ShangHai (Zhou Guoliang, 2006). The third method was based on the fly's fatal temperature, accumulated effective temperature and bioclimate analogous distance. Its showed that the viability areas were $31.64 \%$ in China, the Northern distribution threshold was nearly $(30 \pm 2)^{\circ} \mathrm{N}(\mathrm{Wu}$ Yufen, 2005). The fourth method used GARP ecological niche modeling to predict potential ecological distribution of $B$. dorsalis in China. The results showed host fruit plants have been cultivated at high densities in both suitable and sub-suitable areas, and the major potential geographical distribution of $B$. dorsalis was concentrated south of Changjiang River $\left(97.4^{\circ} \mathrm{E}-121.9^{\circ} \mathrm{E}\right.$, $18.2^{\circ} \mathrm{N}-33.0^{\circ} \mathrm{N}$ ) (Zhou Guoliang, 2007).

Among factors affecting the potential geographical distribution of insect pests, temperature is considered the most pivotal (Ren Lu et al., 2007). As a serious insect pest, a lot of researches are focus on biological characteristics of $B$. dorsalis. Pupal development takes place in the soil and is regulated by two key factors; soil temperature and moisture. These factors are primary determinants of fruit fly distribution. The adult $B$. dorsalis emerges between 
$10.08^{\circ} \mathrm{C}-33.3^{\circ} \mathrm{C}$ (Wu Jiajiao et al., 2003), Vergas reported that the threshold temperature for pupae of $B$. dorsalis was $9.3^{\circ} \mathrm{C}$ (Vergas et al., 1996); Hsu reported $11.1^{\circ} \mathrm{C}$ (Hsu et al., 1973); and $\mathrm{Wu}$ Jiajiao reported $10.08^{\circ} \mathrm{C}(\mathrm{Wu}$ Jiajiao et al., 2003). The emergence rate of $B$. dorsalis was highest when relative soil moisture was between 30\%-80\% (Yuan Shengyong et al., 2004; Lin Jintian et al., 2005). The aforementioned research used atmospheric temperature and soil moisture estimated from rainfall instead of direct measures of soil temperature and moisture which may misestimate the distribution of $B$. dorsalis. Furthermore, soil temperature and moisture vary over 12 months, so this variability should be addressed.

In the present study, the potential geographical distribution of $B$. dorsalis from January to December in China was predicted based on soil temperature and moisture data from Chinese observation stations, the ER (Emergence rate) model which is based on biological observations and statistical analyisis, and analysis using ArcGIS. In addition, four typical monitoring periods of $B$. dorsalis in China are detailed according to the prediction of potential geographical distribution and suitability levels.

\section{MATERIALS AND METHODS}

The two parts of this study include establishing the ER (emergence rate) model of $B$. dorsalis and analyzing the potential geographical distribution and suitability levels using the ER model and displaying distribution patterns using soil temperature and soil moisture of past years in China on an ArcGIS platform.

The $B$. dorsalis samples collected from Huangpu in Guangdong province were selected for the emergence experiment. Eggs of $B$. dorsalis were obtained from adults that had been reared for four generations on artificial diet. Mature larvae (6 days after egg hatch) were placed in moist sand (75\% water) at $29^{\circ} \mathrm{C}$ for pupation. All 7560 pupas were gathered after $24 \mathrm{~h}$ under and held at $25^{\circ} \mathrm{C}$.

The emergence rate (ER) data was collected by placing pupae in a plastic box (high $7 \mathrm{~cm}$, diameter $12.5 \mathrm{~cm}$ ) containing medium soil (Guangdong, DaHan) in an Artificial Climate box (Germany Binder Kbwf240). Data was analyzed using SPSS13.0 (http://www.seekbio.com/soft/1492.html) and ArcGIS 9.0 (Environmental Systems Research Institute. ESRI). Soil temperature and moisture (2001-2003) were obtained from China Meteorological Administration.

The ER model, based on soil temperature and relative water content was obtained from a crossover design experiment conducted from March 2007 to 

ArcGIS

August 2007 at the plant quarantine lab of Guangdong Entry-Exit Inspection and Quarantine Bureau. The design specified 7 soil temperature grades; $9^{\circ} \mathrm{C}$, $14^{\circ} \mathrm{C}, 19^{\circ} \mathrm{C}, 24^{\circ} \mathrm{C}, 29^{\circ} \mathrm{C}, 34^{\circ} \mathrm{C}$ and $39^{\circ} \mathrm{C}$. Six relative water content grades included $0 \%, 20 \%, 40 \%, 60 \%, 80 \%$, and $100 \%$. Experiments consisted of 46 treatments and 3 replications during about 25 days and every box had 60 pupaes. All pupaes were placed $2 \mathrm{~cm}$ under the soil and held in artificial climate boxes. Water was added as needed (Wu Qianhong et al., 1991). The ER of $B$. dorsalis was got and. the ER model was derived by stepwise regression (SPSS 13.0)

Geographic distribution and suitability was calculated for each month of the year for all of China and displayed as maps in ArcGIS. Soil temperature and moisture data were limited, but at least 10 days per month was obtained. Since values were obtained from different locations in different months, the full data set is presented in Table.3. The suitability of $B$. dorsalis was analyzed on the basis of these data and ER model results. The ER of $B$. dorsalis for every location in China was obtained. For each location, suitability was categorized into 4 levels; negligible (where the $B$. dorsalis is unable to occur and survive) $(0 \leq \mathrm{ER} \leq 0.01)$, low $(0.01<\mathrm{ER} \leq 0.2)$, moderate $(0.2<\mathrm{ER} \leq 0.45)$ and high $(0.45<\mathrm{ER} \leq 1)$. Suitability maps were plotted for each month using the inverse distance weight (IDW) raster interpolation.

\section{RESULTS}

\section{1 $\quad$ ER model}

Stepwise regression analysis results:

Stepwise regression ordered the independent variables according to their explanatory power. $\mathrm{X}^{2}$ improved $\mathrm{r}^{2}$ the most followed by $\mathrm{X}, \mathrm{Y}$ and $\mathrm{Y}^{2}$ (Table.1, Table.2). Analysis showed that XY did not contribute to the explanatory power of the model, so it was dropped.

Table 1 Regression model summaries

\begin{tabular}{ccccc}
\hline Model & $\mathrm{R}$ & $\mathrm{R}$ Square & Adjusted R Square & Std. Error of the Estimate \\
\hline 1 & $0.2014(\mathrm{a})$ & 0.0406 & 0.0328 & 0.3888 \\
2 & $0.7843(\mathrm{~b})$ & 0.6151 & 0.6088 & 0.2473 \\
3 & $0.8080(\mathrm{c})$ & 0.6529 & 0.6443 & 0.2358 \\
4 & $0.8471(\mathrm{~d})$ & 0.7175 & 0.7082 & 0.2136 \\
\hline
\end{tabular}


Table.2 Analysis of variance of regression

\begin{tabular}{|c|c|c|c|c|c|c|}
\hline Model & & Sum of Squares & Df & Mean Square & $\mathrm{F}$ & Sig. \\
\hline \multirow{3}{*}{1} & Regression & 0.7928 & 1.0000 & 0.7928 & 5.2442 & $0.0237(\mathrm{a})$ \\
\hline & Residual & 18.7447 & 124.0000 & 0.1512 & & \\
\hline & Total & 19.5375 & 125.0000 & & & \\
\hline \multirow{3}{*}{2} & Regression & 12.0169 & 2.0000 & 6.0085 & 98.2699 & $0.0000(\mathrm{~b})$ \\
\hline & Residual & 7.5205 & 123.0000 & 0.0611 & & \\
\hline & Total & 19.5375 & 125.0000 & & & \\
\hline \multirow{3}{*}{3} & Regression & 12.7555 & 3.0000 & 4.2518 & 76.4859 & $0.0000(\mathrm{c})$ \\
\hline & Residual & 6.7820 & 122.0000 & 0.0556 & & \\
\hline & Total & 19.5375 & 125.0000 & & & \\
\hline \multirow{3}{*}{4} & Regression & 14.0185 & 4.0000 & 3.5046 & 76.8360 & $0.0000(\mathrm{~d})$ \\
\hline & Residual & 5.5190 & 121.0000 & 0.0456 & & \\
\hline & Total & 19.5375 & 125.0000 & & & \\
\hline
\end{tabular}

a Predictors: (Constant), $x x / b$ Predictors: (Constant), $x x, x / c$ Predictors: (Constant), $x x$, $x, y / d$ Predictors: (Constant), $x x, x, y, y y$

Table .1 shows regression model summary, four constants are available including $\mathrm{XX}, \mathrm{X}, \mathrm{Y}$ and $\mathrm{YY}$. Table.2 shows two constants are very significant because of $\mathrm{F}=98.2699>\mathrm{F}_{0.05}$ including $\mathrm{XX}$ and $\mathrm{X}$, three constants are significant $\mathrm{F}=76.4859>\mathrm{F}_{0.05}$, four constants are significant $\mathrm{F}=76.8360>\mathrm{F}_{0.05}$.

The model was available because of $\mathrm{R}^{2}=0.718, \mathrm{~F}=76.836>\mathrm{F}_{0.05}$ and $\mathrm{P}<0.01$. The regression analysis of the ER showed that $\mathrm{P}$ was significant on 0.01 level.

The model chosen for emergence rate determination was

$\mathrm{Z}=-0.0036 \mathrm{X} 2-0.0001 \mathrm{Y} 2+0.1681 \mathrm{X}+0.0123 \mathrm{Y}-1.5170$

Where:

$\mathrm{Z}$ is the $\mathrm{ER}$ (emergence rate) of $B$. dorsalis

$\mathrm{X}$ is the soil temperature

$\mathrm{Y}$ is the soil moisture

\subsection{Potential geographical distribution of $\mathbf{B}$. dorsalis in China:}

Meteorological locations analysis in China: From the Table.3.

As the basis of this model, B. dorsalis suitability was analyzed for 12 months in China combining with the soil data from 2001 to 2003. Since different locations were used by the China Meteorological Service to determine soil temperature and moisture, percents of suitable locations were analyzed. From January to April, moderate and low levels were declining and high levels were increasing, which was the reverse trend from Nov. to Dec. From May to Oct., levels remained stable. It was obviously that two 

ArcGIS

suitable high points were May and Sep., high level was the topmost in whole year, both locations and suitable locations were comprehensive from May to Oct.. There was a turning point in Jul., high suitability levels declined, and other levels increased. This is in accord with the B. dorsalis biology because soil temperature and moisture is beyond its tolerance.

Table. 3 Meteorological locations analysis (Percents of Suitable locations $(\%)=$ Suitable locations / locations Percents Of five grades $(\%)=$ Numbers of suitable locations/ Suitable locations)

\begin{tabular}{|c|c|c|c|c|c|c|}
\hline Month & $\begin{array}{c}\text { Locations } \\
\text { analyzed }\end{array}$ & $\begin{array}{l}\text { Suitable } \\
\text { locations }\end{array}$ & $\begin{array}{l}\text { Percents of Suitable } \\
\text { locations }(\%)\end{array}$ & Suitability levels & $\begin{array}{l}\text { Frequency within } \\
\text { suitable locations }\end{array}$ & $\begin{array}{l}\text { Percents within } \\
\text { each level }(\%)\end{array}$ \\
\hline \multirow{3}{*}{1} & \multirow{3}{*}{43} & \multirow{3}{*}{7} & \multirow{3}{*}{16.28} & high & 2 & 28.57 \\
\hline & & & & moderate & 1 & 14.29 \\
\hline & & & & low & 4 & 57.14 \\
\hline \multirow{3}{*}{2} & \multirow{3}{*}{78} & \multirow{3}{*}{9} & \multirow{3}{*}{11.54} & high & 2 & 22.22 \\
\hline & & & & moderate & 6 & 66.67 \\
\hline & & & & low & 1 & 11.11 \\
\hline \multirow{3}{*}{3} & \multirow{3}{*}{105} & \multirow{3}{*}{40} & \multirow{3}{*}{38.10} & high & 12 & 30.00 \\
\hline & & & & moderate & 10 & 25.00 \\
\hline & & & & low & 18 & 45.00 \\
\hline \multirow{3}{*}{4} & \multirow{3}{*}{103} & \multirow{3}{*}{84} & \multirow{3}{*}{81.55} & high & 42 & 50.00 \\
\hline & & & & moderate & 31 & 36.90 \\
\hline & & & & low & 11 & 13.10 \\
\hline \multirow{3}{*}{5} & \multirow{3}{*}{103} & \multirow{3}{*}{102} & \multirow{3}{*}{99.03} & high & 100 & 97.09 \\
\hline & & & & moderate & 1 & 0.97 \\
\hline & & & & low & 1 & 0.97 \\
\hline \multirow{3}{*}{6} & \multirow{3}{*}{103} & \multirow{3}{*}{103} & \multirow{3}{*}{100} & high & 99 & 96.12 \\
\hline & & & & moderate & 3 & 2.91 \\
\hline & & & & low & 1 & 0.97 \\
\hline \multirow{3}{*}{7} & \multirow{3}{*}{103} & \multirow{3}{*}{97} & & high & 63 & 64.95 \\
\hline & & & 94.17 & moderate & 33 & 34.02 \\
\hline & & & & low & 1 & 1.03 \\
\hline & & & & high & 88 & 94.62 \\
\hline 8 & 93 & 93 & 100 & moderate & 5 & 5.38 \\
\hline & & & & low & 0 & 0.00 \\
\hline & & & & high & 93 & 91.18 \\
\hline 9 & 103 & 102 & 99.03 & moderate & 9 & 8.82 \\
\hline & & & & low & 0 & 0.00 \\
\hline & & & & high & 33 & 49.25 \\
\hline 10 & 102 & 69 & 67.65 & moderate & 17 & 25.37 \\
\hline & & & & low & 19 & 28.36 \\
\hline & & & & high & 6 & 28.57 \\
\hline 11 & 100 & 21 & 21.00 & moderate & 5 & 23.81 \\
\hline & & & & low & 10 & 47.62 \\
\hline & & & & high & 2 & 25.00 \\
\hline 12 & 57 & 8 & 14.04 & moderate & 1 & 12.50 \\
\hline & & & & low & 5 & 62.50 \\
\hline
\end{tabular}

Four months (Feb., Mar., Jul. and Oct) had visible change. Each map indicates the geographic distribution of each suitability level.

The February map showed that the suitable areas were concentrated on the south of China including Yunnan, Sichuan, Guizhou, Guangdong and 
Hainan. High level suitable areas were the south of Yunnan and southwest of Guangxi.

The Mar. map suitabilities are similar to reported local observations except for the southeast of Shandong including Laiyang (moderate level, $36.58^{\circ} \mathrm{N}$ ), Weifang (moderate level, $36.45^{\circ} \mathrm{N}$ ) and lvxian (high level, $35.35^{\circ} \mathrm{N}$ ), which foreshadoows $B$. dorsalis spreading from the south to the north year by year in China because from its last reported latitude of $33^{\circ} \mathrm{N}$ (Zhou Guoliang et al., 2007) (Fig.1).

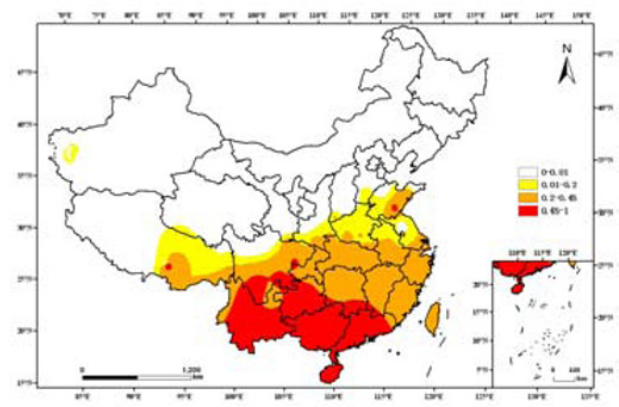

Fig.1: Mar. The potential geographical distribution of $B$. dorsalis and four levels including negligible $(0 \leq \mathrm{ER} \leq 0.01)$, low $(0.01<\mathrm{ER} \leq 0.2)$, moderate $(0.2<\mathrm{ER} \leq 0.45)$ and high $(0.45<\mathrm{ER} \leq 1)$

The July map showed that the north of Jiangxi and the west of Hubei were low level suitable areas due to soil temperature and moisture being very high, a limitation showed by the ER. Likewise, the map showed the major areas of moderate level suitability in the south of China.

From the map of Oct. about suitable information of $B$. dorsalis, the results showed the north of China including Heilongjiang and Jilin were negligible. Suitable areas were reduced from the north to the south of China. But the east of Xinjiang including Shache $\left(38.26^{\circ} \mathrm{N}\right)$ which was ought to be regarded was high level suitability. Maqu $\left(34^{\circ} \mathrm{N}\right)$ from Gansu province was negligible because its soil temperature was very low. (Fig.2)

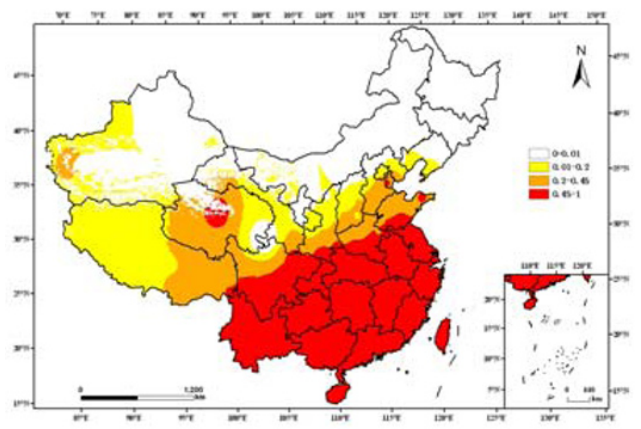

Fig.2: Oct. The potential geographical distribution of $B$. dorsalis and four levels including negligible $(0 \leq \mathrm{ER} \leq 0.01)$, low $(0.01<\mathrm{ER} \leq 0.2)$, moderate $(0.2<\mathrm{ER} \leq 0.45)$ and high $(0.45<\mathrm{ER} \leq 1)$ 


\subsection{Conclusions}

This study confirms other research as well as observations of $B$. dorsalis distribution throughout China. Major suitable locations occur south of $\pm 35^{\circ} \mathrm{N}$ with little occurrence north of $35^{\circ} \mathrm{N}$.

The distribution expanded and contracted over the year with the wider distribution occurring in the summer months. Environmental conditions in high level locations correlated with optimal development conditions predicted by the emergence rate model. The results indicated that soil temperature affected the potential geographical distribution of $B$. dorsalis in China and suitable areas changed with the season.

In winter months the suitable areas for $B$. dorsalis in China were concentrated in south China, such as Yunnan, Guangxi and Guangdong. In March, $B$. dorsalis started to spread from south to north. At the beginning of April, the suitability of $B$. dorsalis was high in south China, where $81.55 \%$ of the locations were suitable. In that area suitability was rated high $(50 \%)$ and moderate $(36.9 \%)$, indicating that pest management actions against $B$. dorsalis shoud commence at this time. From May to December, major portions of China contained suitability areas, but it was obvious from the map that suitability in south China declined in July from high to moderate because soil temperatures exceeded the emergence threshold temperature of $B$. dorsalis, and high rainfall frequency in this period suppressed emergence.

\section{DISCUSSION}

\subsection{The potential geographical distribution analysis of $B$. dorsalis in China}

Yunnan suitability analysis: Yunnan was one of the important suitable areas during winter months and provided the source population of $B$. dorsalis for the coming year with adult populations peaking in July. This was also reported by Jiang Xiaolong and Chen Peng (Jiang Xiaolong et al., 2001; Chen Peng et al., 2007). The results indicated that Menzi(a county of Yunnan) didn't occur seasonally, which was different with Liuku(a county of Yunnan) in province, the south of Yunnan especially Menzi was suitable for occurring of B. dorsalis in whole year (Chen Peng et al., 2007).Hei Longjiang suitability analysis: Hei Longjiang areas have high suitability from May to September, however, these results are misleading since $B$. 
dorsalis cannot survive the winter in this area.ShangHai suitability analysis: B. dorsalis emergence may happen at the beginning of April, but was highest from May to October. This correlates with the report of Zhou Guoliang who found progressively earlier emergence over several years. The fruit fly was found firstly in August in 2001, in June in 2002, in June in 2003 and in May in 2004 and 2005 (Zhou Guoliang, 2006).Qinghai, Tibet and Xinjiang areas suitability analysis: Suitability was high from May to September, but the results could not be substantiated because of the lack of host plants and a difficult winter.

\subsection{Monitoring and trapping periods}

This study indicated four monitoring and trapping periods for fruit fly emergence in China. Two months are not suitable and monitoring should be suspending at these times. The first period was from April 1 to October 31, and monitoring areas include Liaoning, Jilin, Heilongjiang, Inner Mongolia, Qinghai, Beijing, Tianjin, Hebei, Henan, Shandong, Shanxi, Shaanxi, Gansu and Ningxia. The second period, from March 1 to October 31 included Xinjiang, Zhejiang and Tibet. The third period was from March 1 to November 31 and included Sichuan, Chongqing, Guizhou, Jiangxi, Hubei, Hunan, Anhui, Jiangsu, Shanghai, Fujian and Taiwan. Monitoring should take place throughout the year in Guangdong, Guangxi, Yunnan, Hainan.

In summary, we reported that two important natural factors (soil temperature and moisture) determined the potential geographical distribution of $B$. dorsalis over 12 months in China, and that the ER model can be used to predict where and when these conditions are suitable for $\mathrm{F}$ emergence. This model may also apply to other countries. The ER model will be improved with future research.

\subsection{Management countermeasures}

Quarantine measures should be strengthened domestically as well as at the borders (inspection and quarantine). The critical tasks of border inspection and quarantine are port inspection and quarantine from May to September, especially from imports from these continents: America (America, Chile), Oceania (Australia, New Zealand, Nauru), Asia (Bangladesh, Bhutan, Hindustan, Kisan, Japan, Laos, Malaysia, Burma, Nepal, Oman, Pakistan, Philippines, Singapore, Sri Lanka, Thailand, United Arab Emirates, Viet Nam), because many areas of China are suitable for fruit fly during this time. In addtion, domestic inspection and quarantine should address the transport of fruits and vegetables from south China to areas in the north, such as 
Guangdong, Guangxi, Hunan, Guizhou, Fujian, Hainan, Yunnan, Szechwan, Hongkong, Macao, Taiwan and so on. Quarantine measures ought to be reinforced to prevent fruit and vegetable infestations.

\section{ACKNOWLEDGMENTS}

The authors would like to thank Liang Guangqin, Mo Renhao, Hu Xuenan, Liu Haijun, Li Chunyuan and all other officers of Guangdong Inspection and Quarantine Technology Center to support to the experiment. This study received financial support from '973' project (the national development project on key basic research) (2002CB111405) and 11th Five-Year national scientific and technological support Plan 'Invasive species risk assessment and early warning technology of China' (2006BAD08A15).

\section{REFERENCES}

Chen Lin, M. D. Korzukhin, Chen Dengfa, et al. The analysis for the red imported fire ant solenopsis invicta (Hymenoptera: Formicidae) distribution in China based on $3 \mathrm{~S}$ technology, climate model and colony dynamic model, Acta Phyophylacica Snica, 2006, 33(4): 384-390(in Chinese)

Chen Peng, Ye Hui. Population dynamics of Bactrocera dorsalis (Diptera: Tephritidae) in Liuku, Yunnan with an analysis of the influencing factors, Acta Entomologica Sinica, 2007, 50(1): 38-45(in Chinese)

Christensom L. D., Foote R. H.. Biology of fruit fly, Annu. Rev. Entomol, 1960, 5: 171-192

Cook W. C. Notes on predicting the probable future distribution of introduced insects [J].Ecology, 1931, 12(2): 245-247.

Cook W. C. The distribution of the alfalfa weevil Phytonomus Posticus Gyll., a study in physical ecology [J].J Agri Res, 1925, 30(5): 479-491

Elith J. C., Graham H., Anderson R. P.. Novel methods improve prediction of species' distributions from occurrence data. Ecography, 2006, 29: 129-151

Fan Jingan. Studies on the assessment of potential establishment of orient fruit (Bactrocera dorsalis) in China with synthetic judgment on fuzzy mathematics, Plant Quarantine, 1998, 12(2): 76-80(in Chinese)

Ge Quanqing, Wen Fujiang. Predicting the potential geographical distribution of flavescence doreand its vector Scaphoideus titanus Ball in China using DIVA-GIS, Acta Phyophylacica Snica, 2006, 33(1): 51-58(in Chinese)

Hernandez P. A., Graham C. H., Master L. L. and Albert D. L., The effect of sample size and species characteristics on performance of different species distribution modeling methods .Ecography, 2006, 29: 773-785.

Hou Bohua, Zhang Runjie. Potential geographical distribution of the fruit fly Bactrocera dorsalis in China as predicted by CIMEX, Acta Ecological Snica, 2005, 25(7): 15691574(in Chinese) 
Hsu E. S.. Biological studies on the oriental fruit fly (Dacus dorsalis). Plant Prot. Bull. (Taiwan), 1973, 5: 59-86

Huang Kehui, Guo Qiongxia. Risks analysis for Bactrocera dorsalis, Entomological Journal of East China, 2005, 14(3): 251-255(in Chinese)

Huang Suqing, Han Richou. Advance in the Research on the quarantine pest Bactrocera dorsalis, Chinese Bulletin of Entomology, 2005, 42(5): 479-484 (in Chinese)

IIE Distribution Maps of Pests. Wallingford: CAB International, 1994, Series A: 109

IIE Distribution Maps of Pests. Wallingford: CAB International, 1994, Series A: 553

Jiang Xiaolong, He Wanzhong, Li Cuiju, et al. Study on the biology and survival of Bactrocera dorsalis in the border region of Yunnan, Journal of southwest Agricultural University, 2001, 23(6): 510-513, 517(in Chinese)

Liang Guanghong, Chen Jiahui, Yang Jianquan, et al. Advance in Research of Bactrocera dorsalis (Hendel) in China, Entomological Journal of East China, 2003, 12(2): 90-98(in Chinese)

Liang Guangqin, Liang Guozhen, Lin Ming, et al. The introduction and control of Tephritidae, Guangdong Science \& Technology Press, 1993: 18-30(in Chinese)

Lin Jintian, Liang Guangwen, Zeng Lin, et al. Influence of soil moisture on the survival of oriental fruit fly (Bactrocera dorsalis) pupae, 2005, 42(4): 416-418(in Chinese)

Nuttonson M. Y. Ecological Crop geography of China and its agroclimatic analogues in North America [A]. Am. Inst. Crop ecology[C]. Silrer Spring M d., 1947: 328-341

Ren $\mathrm{Lu}, \mathrm{Lu}$ Yonglin, Zeng Lin. Cold hardiness of pupae and over-wintering a adults from natural populations of Bactrocera dorsalis (Hendel)(Diptera: Tephritidae) in China, Acta Entomologica Sinica, 2007, 50(6): 588-596(in Chinese)

Song Hongmin, Zhang Qinfen, and Han Xuemei, et al. CLIMEX: Professional biological software for predicting potential geographical distribution of species, Entomological Knowledge, 2004, 41(4): 379-386(in Chinese)

Stephens A. E. A., Kriticos D. J., Leriche A.. The current and future potential geographical distribution of the oriental fruit fly Bactrocera dorsalis (Diptera: Tephritidae), Bulletin of Entomological Research, 2007, 97: 369-378

Sutherst R.W, Maywald G.. A Climate Model of the Red Imported Fire Ant, Solenopsis Invicta Buren (Hymenoptera: Formicidae): Implicaitons for Invasion of new regions, Particularly Oceania, Population Ecology, 2005, 34: 317-335

Sutherst R.W., Maywald G.. Form CL IMEX to PESKY a generic expert system for pest risk assessment [J]. Bull OEEP/ EPPOBull, 1991, 21: 595-608.

Vergas R. I, Waslsh W. A., Jang E. B., et al. Surival and development of immature stages of four Hawaiian fruit flies(Diptera: Tephitidae) rear at five constant temperatures. Ann.Entom.Soc.Am, 1996, 89: 64-69

Wang Yunsheng, Xie Bingyan, Wan Fanghao, et al. Application of ROC curve analysis in evaluating the performance of alien species potential geographical distribution models, Biodiversity Science, 2007, 15(4): 365-372(in Chinese)

Wei Shuqiu. The introduction of similarity distance of agricultural climate, Journal of Beijing Agricultural University, 1984, 10(4): 427-428

Wu Jiajiao, Liang Fan, Liang Guangqin. The research of Bactrocera dorsalis (hendel) (Diptera: Tephritidae) between developmental rate and temperature, Inspection and Quarantine Science, 2003, 13(5): 17-18(in Chinese)

$\mathrm{Wu}$ Qianhong, Shao Zexin, Shudeming. Insect Ecology experiment, Fudan University publishing house, 1991: 271 
Wu Yufen. Geographical distribution model of Oriental fruit fly, Journal of Fujian Agriculture Forestry University (National Science Edition), 2005, 34(2): 169-171(in Chinese)

Xiong Yan, Xiang Yong, Bao Yunxuan, et al. Study on the suitable establishment of Bactrocera dorsalis Hendel in Jiangsu Province, China. Journal of Nanjing Agricultural University, 2006, 29(4): 48-52(in Chinese)

Yuan Shengyong, Kong Qiong, Xiao Chun, et al. Influence of drowning and pupal depth on the duration and eclosion rate of Bactrocera dorsalis (hendel), Journal of Mountain Agriculture and Biology, 2004, 23(6): 486-488(in Chinese)

Zhang Qingyuan, Lin Zhenji, Liu Jinyao. Study on the biology of oriental fruit fly, Entomological Journal of East China, 1998, 7(2): 65-68(in Chinese)

Zhang Runjie, Hou Bohua. Assessment on the introduction risk of Bactrocera dorsalis through imported fruits with fuzzy mathematics, Acta Phyophylacica Snica, 2005, 48(2): 221226(in Chinese)

Zhou Guoliang, Chen Chen, Ye Jun, et al. Predicting potential ecological distribution of Bactrocera dorsalis in China using GARP ecological niche modeling, Acta Ecological Snica, 2007, 27(8): 3362-3369(in Chinese)

Zhou Guoliang, Li Weimin, Yin Liping, et al. Methods of assessment of pest potential establishment and some key points on research of establishment, Plant Quarantine, 2006, 20(supplement): 1-6(in Chinese)

Zhou Guoliang, Ye Jun, Yuan Ping, et al. The invasive mechanism of Bcatocera dorsalis in Shanghai, Plant Quarantine, 2006, 20(supplement): 44-46(in Chinese)

Zhou Guoliang, Yin Liping, Li Weimin, et al. Quantitative assessment of the probabilities of introduction of the oriental fruit fly using probability model, Plant Quarantine, 2006, 20(supplement): 10-13(in Chinese)

Zhou Yousheng, Sheng Farong, Zhao Huanping. Study on the biology of Bactrocera dorsalis and synthetically control, Journal of southwest Agricultural University, 1996, 18(3): 210213(in Chinese) 